\title{
En la base de la ruta: barreras de acceso y estrategias de atención en la ruta de declaración y registro de víctimas del conflicto**
}

\author{
Street-level bureaucrats: Difficulties to Access and Care Strategies \\ in the Declaration and Registration Process for Victims \\ of Army Conflict
}

Na base da rota: barreiras de acesso e estratégias de atenção no processo de declaração e registro de vítimas do conflito

\footnotetext{
* Magister en Derecho de la Universidad de los Andes, especialista en Cultura de Paz y Derecho Internacional Humanitario de la Pontificia Universidad Javeriana y abogada de la Universidad Icesi. Sus intereses de investigación están enfocados en el activismo judicial y burocrático en relación con la adjudicación de derechos económicos, sociales y culturales y la inclusión social. Correo electrónico: grecalde1@icesi.edu.co

** Este artículo hace parte de los hallazgos del proyecto Evaluación del funcionamiento del Sistema Nacional de Atención Integral a la Población Desplazada del Grupo de Investigación Precedente del programa de Derecho de Icesi; fue dirigido por el profesor Mauricio Lenis y se ejecutó durante el año 2013 con financiamiento del fondo de investigación de la Universidad Icesi. Artículo de investigación recibido el 10/06/2016 y aceptado el o6/08/2016.
} 


\section{Cómo citar}

RECALDE CASTAÑEDA, G. (2016). En la base de la ruta: barreras de acceso y estrategias de atención en la ruta de declaración y registro de víctimas del conflicto. Revista CS, no. 20, pp. 123142. Cali, Colombia: Facultad de Derecho y Ciencias Sociales, Universidad Icesi. 


\section{Resumen}

Abstract

Resumo

Este artículo propone una evaluación de la política pública de atención a víctimas a partir del diagnóstico de las prácticas cotidianas de las agencias estatales del nivel local y su contribución al proceso de restablecimiento de derechos. A través de un estudio de caso del funcionamiento de la ruta de declaración y registro de víctimas del conflicto armado de la Unidad de Atención a Víctimas de Cali, se identifican la presencia de barreras de acceso, individuales e institucionales. Las primeras impiden el goce efectivo de derechos de las víctimas a nivel individual, y las segundas, limitan la operación de las burocracias de base del sistema de atención. Los funcionarios del nivel de base de estas estructuras implementan estrategias formales e informales algunas de las cuales mitigan, aunque de forma limitada, los efectos negativos de las barreras identificadas.

\section{PALABRAS CLAVE:}

Ruta de atención a víctimas | políticas públicas | burocracias de base

Based on a diagnosis of the daily practices of state agencies at local levels and their contribution to the process of restoring fundamental rights, this paper proposes an evaluation of the public policy conceived for attention to the internal army conflict's victims. By the application of a case study - on the Declaration and Registration Process developed by the Victim's Assistance and Orientation Unit of Cali-it identifies two main access hindrances: the ones affecting the exercise of the victim's rights and the institutional interferences that limiting the bureaucracies operation. Street-level bureaucrats have been implementing formal and informal strategies which mitigate some of the negative effects of such identified hindrances.

\section{KEYWORDS:}

Victims of army conflict | public policy | street-level bureaucrats 
Este artigo propõe uma avaliação da política pública de atenção às vítimas a partir do diagnóstico das práticas cotidianas das agências estatais a nível local e sua contribuição para o processo de restauração de direitos. Através de um estudo de caso da operação do processo de declaração e registro de vítimas do conflito armado na Unidade de Atenção às Vítimas de Cali, identifica-se a presença de barreiras de acesso individuais e institucionais. As primeiras impedem o gozo efetivo dos direitos das vítimas a nível individual e as segundas limitam o funcionamento das burocracias de base do sistema de atenção. Os funcionários de nível base destas estruturas usam estratégias formais e informais, algumas das quais mitigam, embora de forma limitada, os efeitos negativos das barreiras identificadas.

\section{PALAVRAS CHAVES:}

Processo de atenção às vítimas | políticas públicas | burocracias de base | Cali-Colômbia 


\section{Introducción}

Este artículo explora las barreras de acceso a la ruta de declaración y registro para las víctimas del conflicto armado, así como las prácticas informales que los burócratas del nivel de base de la ruta incorporan a su actuación diaria para el cumplimiento de sus funciones. Sostendré que algunas de estas prácticas directa o indirectamente mitigan los efectos de dichas barreras y algunas otras las refuerzan. Mi premisa de trabajo implica una aproximación al sistema burocrático desde la base de su funcionamiento, no pensado propiamente en una estructura jerarquizada y monolítica, sino difusa (Buchely, 2014). El Sistema Nacional de Atención y Reparación a Víctimas - SNARIV-está compuesto en su fase operativa local de órganos vinculados a los entes territoriales como la Personería Municipal, cuyos funcionarios son los encargados de ofrecer orientación por primera vez a las víctimas que se acercan a rendir la declaración para la inscripción en el Registro Único de Víctimas (RUV). Diagnosticar lo que en la práctica cotidiana ocurre en esta primera transacción entre las víctimas y el estado, encarnado en el funcionario, permite comprender la raíz de aquellos obstáculos estructurales que las víctimas encuentran para acceder a sus derechos a la verdad, justicia y reparación.

Este artículo hace parte de los hallazgos del proyecto "Evaluación del funcionamiento del Sistema Nacional de Atención Integral a la Población Desplazada" del Grupo de Investigación Precedente del programa de Derecho de Icesi. El propósito del proyecto era diagnosticar las barreras que impiden el acceso de la población víctima a una adecuada y pronta atención y orientación con relación a sus derechos, así como las pautas de atención empleadas por los funcionarios de la ruta de registro y declaraciones que atienden a la población desplazada declarante - PDD-. La investigación utilizó como enfoque metodológico cualitativo el estudio de caso, entendido como una exploración profunda de las múltiples perspectivas y complejidades únicas de un proyecto, una política pública, una institución, una persona, un programa, o un sistema en el contexto de "la vida real". Este tipo de investigación permite generar un conocimiento útil sobre el desarrollo de políticas públicas (Simons, 2009: 21).

En esta investigación se privilegió, un estudio de caso intrínseco-instrumental (Stake, 1995, “The Art of Case Study Research", citada en Simons, 2009), puesto que nos interesaba comprender el mundo de los funcionarios de la ruta de atención primaria de la ciudad de Cali, pero al tiempo, usar los hallazgos para evaluar y formular recomendaciones sobre la política pública implementada en el marco de la Ley 1448 de 2011 (Ley de víctimas). Los datos para este artículo provienen de entrevistas semiestructuradas a dos funcionarias de la ruta de educación, a una de la ruta de salud, y a seis de la ruta de declaración y registro ${ }^{1} \mathrm{y}$ observaciones en campo realizados durante los meses de junio y septiembre de 2013. Esto se complementó con el análisis documental de los 
protocolos de atención y algunas sentencias de la Corte Constitucional referentes al tema de registro.

En la primera parte del texto se relata brevemente la dinámica del desplazamiento en la ciudad de Cali y la estrategia de atención primaria delimitada por la política pública local de atención a víctimas del conflicto. En los apartes siguientes se presentan los hallazgos de la investigación. La clasificación y descripción de las barreras de acceso institucionales e individuales (2) y las estrategias o prácticas de atención empleadas por los funcionarios de la ruta de declaración y registro del Municipio de Cali (3) usando el marco analítico de la teoría de los valores públicos de Bozeman (2007) y el constitucionalismo democrático de Rosenbloom (2007). Finalmente, se plantea la conclusión del estudio de caso.

\section{La dinámica del desplazamiento forzado en Santiago de Cali}

La migración forzosa en la región del Pacífico tiene entre sus causas la integración de la región a nuevos procesos económicos y productivos (regionales, nacionales e internacionales), como las plantaciones de palma africana, la presencia de empresas camaroneras, de extracción de minerales y madera (Barbary y Urrea, 2004); así como procesos por fuera de la ley vinculados con el narcotráfico y la aparición y asentamiento de grupos armados al margen de la ley en zonas como el Urabá antioqueño o el Valle del río Cauca. Se trata de actores tradicionales del conflicto como las FARC y el ELN, y otros emergentes como las denominadas bandas criminales (en adelante Bacrim) tales como "La Empresa”, "Los Urabeños”, “Los Rastrojos”, “Los Machos”, "Las Águilas Negras”, “Los Erpac” y “La Cordillera” (CODHES, 2013, pág. 32);(Personería de Cali, 2014). Los enfrentamientos entre facciones armadas ocasionan el recrudecimiento del conflicto social y armado, y el desplazamiento forzado.

El departamento del Valle del Cauca ${ }^{2}$ es uno de los centros de recepción y expulsión de estas migraciones. Este departamento comparte con Antioquia, Cauca y Nariño las mayores tasas de recepción de población desplazada (PD) 3 . Las cifras de personas que arriban en calidad de desplazadas se aproximan a 20.000 o más al año. Igualmente,

2. Para la primera década del presente siglo, de acuerdo con el Censo de 2005 (Mosquera, Laó-Montes \& Rodríguez, 2010), la población total del Valle del Cauca ascendía a 4.052.535, de estos el 27\% son afro (1.092.169 personas), muchos de ellos oriundos de otras regiones del pacifico colombiano. En solo este departamento se aglutina el 25,3\% de la población afro nacional que se estima es de 4.311.757.

3. Un dato que ejemplifica esta afirmación se desprende de los resultados de la encuesta del Sistema de información RUPD (Registro Único de Población Desplazada-Acción Social) del año 2004, en la cual, a la pregunta sobre las preferencias de los individuos sobre el lugar seleccionado para desplazarse, se observa que el Valle 
las tasas de expulsión son altas, y el Valle es el sexto departamento más afectado por desplazamientos masivos en el país (CODHES, 2014a). La capital del departamento, Santiago de Cali, es el principal receptor de PD proveniente de ciudades como Buenaventura y Pradera, y de otros departamentos como Cauca, Nariño y Chocó (Personería Municipal de Cali, 2014). En Santiago de Cali, por cada 100.0oo habitantes llegan cerca de 1.000 personas desplazadas (CODHES, 2013). Unas $138.060^{4}$ víctimas del conflicto están asentadas en la ciudad, cifra que de acuerdo a los informes de CODHES (2014b), solo correspondería a la de población desplazada. De acuerdo con los datos de CODHES (2014b) y los de la Red Nacional de Información de la Unidad de Víctimas - RNI- (2014), en los tres últimos años la media de arribos anuales de PD ha sido de 7.184 personas. Para el 2013 (año de la investigación), según las cifras de la RNI en el municipio se reportaron $11.059^{5}$ víctimas, de estas 5.947 declararon desplazamiento forzado ${ }^{6}$. A esta cifra debe sumarse el incremento de migraciones intraurbanas ocasionadas por la presencia de Bacrim en las zonas de oriente y de ladera, cuyas incursiones dejaron como saldo 1.585 personas desplazadas en el 2013 (RNI, 2014).

Una de las explicaciones del flujo de migración hacia y desde el interior de la ciudad de Cali, es la existencia de redes sociales y de apoyo, las cuales están compuestas por familiares, amigos o conocidos que llegaron a la ciudad por migraciones económicas o desplazamientos forzados previos. La construcción de una memoria colectiva es lo que permite al migrante encontrar los vínculos correctos al momento de tener que huir y buscar un lugar de acogida para sobrevivir. El desplazamiento es una red territorial de capacidad que emerge de la guerra y de los movimientos de los desplazados como respuesta a las acciones de los agentes armados; su flujo depende del movimiento de

del Cauca es la primer opción para los pobladores del Cauca, Nariño, Risaralda, Putumayo y Chocó. Para los desplazados del propio departamento, después del Valle, optan por Nariño, Risaralda, Caldas, Antioquia y Bogotá. (Salazar, Castillo y Pinzón, 2004).

4. Red Nacional de Información. Unidad para la Atención y Reparación Integral a las Víctimas. A corte del 21 de enero de 2014. Datos correspondientes al periodo 1996-2013. Citado por la Personería de Cali (2014).

5. Otro reporte de la misma identidad plantea que fueron 12.862 víctimas, no obstante, se aclara que este reporte no refleja el total de víctimas únicas debido a que una persona puede haber reportado hechos en varios años. Ahora bien, respecto a la diferencia entre uno y otro reporte, la misma se explica porque la actual base de datos que maneja la Red Nacional de Información se compone de las bases de datos de programas específicos preexistentes, entre ellos el de desplazamiento forzado impulsado por la Ley 397 de 1997, y solo hasta ahora se está unificando toda la información en una sola gran central estadística. Notas de la reunión de la Mesa de Atención y Registro del proceso de seguimiento a la sentencia T-025, citada por CODHES y realizada el día 22 de enero de 2014. Bogotá.

6. Los otros hechos victimizantes contemplados en la Ley de Víctimas son: abandono o despojo forzado de tierras, acto terrorista, atentados, combates u hostigamientos, delitos contra la libertad y la integridad sexual, desaparición forzada, homicidio, minas antipersona, munición sin explotar o artefacto explosivo, pérdida de bienes muebles o inmuebles, secuestro, tortura, vinculación de niños, niñas y adolescentes, y amenazas. 
personas entre nodos expulsores y receptores. Dicho movimiento se detiene una vez la persona desplazada identifica un sitio apropiado para permanecer en él, o cuando coincide con el alcance de su red social (Castillo y Pinzón, 2008). Sin embargo, estos sitios están ubicados en los cordones de pobreza de la ciudad, como la zona de oriente (que corresponde a las comunas 6, 7, 13, 14, 15, 16 y Desepaz') y en las comunas 18 y 20 de la zona de ladera, ${ }^{8}$ lo que acentúa la condición de vulnerabilidad y las desigualdades económicas, sociales, físicas, culturales y étnicas. En consecuencia, no se produce una verdadera integración de la población migrante, o si se hace es desde la informalidad, el trabajo clandestino y mal remunerado, o desde la asistencia social del Estado. A pesar de estas condiciones desfavorables para el reasentamiento, la consolidación de Cali como centro de recepción es inevitable. La misma está relacionada con su calidad de capital de Departamento, lo que genera la apariencia de que se trata de una ciudad más asequible en términos de transporte terrestre, ofertas laborales, e incluso, por su tamaño, proporciona una sensación de seguridad para el desplazado que huye por temor a las amenazas directas por parte de los grupos armados (Barbary y Urrea, 2004).

La respuesta institucional del municipio para hacer frente a la crisis humanitaria que representa el desplazamiento, entre 2011 y 2013, fue la implementación del Plan Integral Único ${ }^{9}$ de atención a la PSDF. Este plan tenía como objetivo incidir en la disminución de los niveles de vulnerabilidad de la PD asentada en la ciudad ${ }^{10}$. Desde el 2012, las medidas

7. Este agrupamiento de comunas se conoce como "El Distrito de Agua Blanca". Su surgimiento ha sido relacionado con diversos factores sociales. A finales de los años setenta en esta zona tuvieron lugar procesos de invasión impulsados por la ausencia de suelo urbano destinado a vivienda de interés social. También se habla de la negociación ilegal de terrenos inundables del margen de protección del río Cauca, no apropiados para vivir por los riesgos que ello implicaba. Otro factor social importante para la constitución y crecimiento acelerado del Distrito de Aguablanca, son las migraciones masivas desde otros lugares del Pacífico afectados por desastres naturales, por situaciones de violencia agraria y por pobreza extrema, que llegaban atraídos por la posibilidad de encontrar empleos y "un mejor lugar donde vivir" (Barbary y Urrea, 2004).

8. Estos sitios son caracterizados como barrios populares de estrato bajo y bajo-medio, con una alta densidad demográfica; además presentan los índices más elevados de violencia y necesidades básicas insatisfechas, en relación con los sectores de la ciudad que corresponden a estratos medio-alto. Cabe anotar que la población vive en asentamientos de desarrollo urbano incompleto o informales (mejor conocidos como invasiones) como Brisas de Comuneros, La Colonia Nariñense y El Jarillón del Río Cauca. Se trata de zonas donde no es permitida la construcción de vivienda por su proximidad a espacios de protección o de alto riesgo medio ambiental (Personería Municipal de Cali, 2014).

9. La elaboración del PIU está regulada en la Ley 1190 de 2008. Esta dispone que los comités municipales, departamentales y distritales deban formular e implementar estos planes, los cuales estarán articulados con los planes de desarrollo y los presupuestos locales. De acuerdo con la Corte, el PIU es una herramienta de planeación estratégica que permite la participación de las víctimas y que permite coordinar acciones para prevenir y atender el desplazamiento forzado. (Auto 052 de 2008 y 383 de 2010).

10. La dirección estratégica del plan estaba a cargo de la Asesoría de Paz y la Personería de Cali, la primera una entidad adscrita a la Secretaría General; y la segunda, el órgano de control interno y de promoción de la cultura ciudadana y los derechos humanos. 
de política pública del PIU se articularon a la formulación del Plan de Atención Territorial a Víctimas (PAT), el cual responde al mandato del artículo 174 de la Ley 1448 de 2011 y el Artículo 254 del Decreto 4800 de 2011, según el cual las entidades territoriales deben implementar cada cuatro años un plan que contemple medidas de prevención, rutas de asistencia y atención y medidas de reparación integral acordes al contexto y dinámicas locales. De acuerdo con el PAT de Cali, la ruta de asistencia y atención enfocada en la entrega de la ayuda humanitaria a víctimas, tiene cuatro momentos. En el primero, la persona recibe un taller de orientación seguido por la toma de la declaración del hecho victimizante a cargo de los funcionarios de la Personería; posteriormente, la persona es caracterizada y recibe asistencia psicosocial y se verifica su afiliación al sistema de salud. Segundo, la persona es priorizada para entrega de ayudas inmediatas (bono alimentario, estadía en hogar de paso o auxilio funerario) si durante la caracterización se encuentra que se trata de un desplazamiento ocurrido hace menos de tres meses y/o que la persona está en situación de vulnerabilidad. Si la persona recibe alguna de estas ayudas, pasa a un tercer momento que consiste en la asesoría sobre cómo utilizarlas de forma eficiente. Un cuarto momento es el seguimiento que se hace a fin de establecer la inclusión de la víctima en el RUV, en caso negativo la Personería deberá suministrar asesoría legal para la elaboración del recurso de reposición contra la resolución de la UNARIV que niega la inclusión. Este en el momento de la declaración o paso primero que enfocó esta investigación.

\section{Las barreras del acceso: obstáculos institucionales e individuales}

A partir del trabajo de campo y el estudio de los Autos que la Corte Constitucional ha emitido en el proceso de seguimiento al estado de cosas inconstitucional de la población en situación de desplazamiento forzado, declarado en la Sentencia T-025 de 2004 ${ }^{11}$, en la investigación se propone una distinción entre barreas individuales y barreras institucionales. Las primeras son todos aquellos obstáculos que impiden el goce efectivo de

11. En el año 2004 la Corte Constitucional procedió a analizar de manera conjunta 109 expedientes correspondientes al mismo número de acciones de tutela interpuestas por personas en situación de desplazamiento, cuyo núcleo familiar estaba conformado en promedio por 4 o más personas. Los demandados eran: Acción Social, el Departamento Administrativo de la Presidencia de la República, el Ministerio de Hacienda y Crédito Público, el Ministerio de Protección Social, el Ministerio de Agricultura, el Ministerio de Educación, el Inurbe, el Incora y el SENA. Del análisis de estos casos la Corte determinó la necesidad de declarar un estado de cosas inconstitucional, figura que implica la existencia de una situación continua que provoca una afectación generalizada a un grupo determinado de la población, y cuya causa es de índole estructural, es decir, que su origen va más allá de la omisión de la entidad demandada, y por lo tanto, su solución exige la acción mancomunada del Estado. 
derechos de las víctimas del desplazamiento forzado a nivel individual y que devienen de factores culturales y del contexto social; y las segundas, son los obstáculos que limitan la capacidad operativa de las instituciones del SNARIV en la etapa de registro y declaración, y que se traducen en una baja calidad en la atención a víctimas.

\section{Barreras institucionales}

\section{Barreras administrativas}

Referidas a la descoordinación respecto a las funciones de las entidades territoriales y las del orden nacional derivadas de una asignación de responsabilidades difusas en la ley y la falta de un mecanismo de priorización de las necesidades de ciertos sectores: registro, registro de tierras, asistencia humanitaria, vivienda, entre otros. Una subcategoría es la insuficiencia en el presupuesto para la atención, la cual implica una pobre capacidad de ejecución en los entes territoriales ${ }^{12}$. En el trabajo de campo se encontraron las siguientes narrativas que dan cuenta de esta barrera institucional:

\section{a. Insuficiencia depersonal operativo: en el edificio de la Unidad Territorial de Cali, diariamente,} 100 personas o más se acercan a solicitar alguno de los servicios que ofrecen las Secretarías de Educación y Salud, el SENA, el ICBF, la Asesoría de Paz o la Personería, que tienen presencia en el lugar con pocos funcionarios. Los entrevistados afirman que el acceso a la ruta de atención se dificulta por la sobredemanda de población que busca ser atendida en la Unidad, en contraste con el escaso número de funcionarios asignados para ello. Por ejemplo, para acceder al proceso de declaración es necesario agendar una cita vía telefónica. No obstante, a la fecha de realización del trabajo de campo, en la Unidad solamente había. dos personas encargadas de esta actividad. La tardanza en la asignación genera retrasos para rendir la declaración. Para una de las funcionarias entrevistadas son necesarios " $m e$ canismos de comunicación entre funcionarios que dinamicen mucho la atención ${ }^{\prime \prime 3}$.

b. Insuficiencia del presupuesto asignado para la operación: de acuerdo con una entrevistada

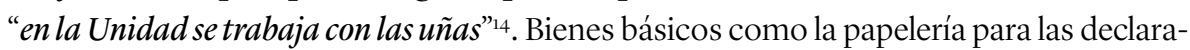
ciones que son tomadas por la Personería en el sitio, escasean. También la distancia física

12. Esta es una falla que la Corte evidencia en el Auto 177 de 2005 que se reitera en los Autos 218 y 266 de 2006, el o07, oo8 y 314 de 2009, y el 383 de 2010. Si bien con la entrada en vigencia de la Ley 1448 de 2011 se diseñó el CONPES 3726 de 2012 para proveer el presupuesto entre 2011-2021, los organismos de Control reportan y la Comisión de Seguimiento y Monitoreo, siguen reportando en todos sus informes que la población desplazada recibe un número insuficiente de ayudas al año, porque básicamente el presupuesto asignado, a pesar de su incremento en más del $50 \%$, es superado por la demanda de población víctima.

13. Entrevista a MRR del SENA, realizada en junio de 2013 en la UAO.

14. Entrevista a S, funcionario de la Personería. Junio de 2013 
entre la Unidad ${ }^{15}$ y el Centro Administrativo Municipal (CAM) limita la conectividad con la banda ancha del Municipio. La Unidad accede a una baja frecuencia de señal que proviene de un Centro de Atención Local cercano pero que es insuficiente para soportar el sistema de declaraciones en línea, cuyo fin es disminuir los tiempos de atención y registro al conectar al municipio con la Subdirección de Registro en Bogotá. A los problemas de conectividad se suman la falta de insumos como lapiceros, almohadilla dactilar, tijeras y otros implementos de oficina.

c. Inestabilidad laboral de los funcionarios vinculados al proceso de declaración: muchos de los funcionarios están vinculados al proceso a través de un contrato de prestación de servicios. Esto genera, por un lado, inestabilidad laboral para el contratista, quien debe cubrir sus gastos de salud y pensión, además no goza de bonificaciones, vacaciones o cesantías. Por otro lado, la asignación de contratos depende de la coyuntura política del municipio y de la distribución de poder entre los principales actores de este campo ${ }^{16}$.

d. Diseño basado en el asistencialismo: varios de los funcionarios entrevistados plantean la existencia de una cultura asistencialista fomentada por el Estado que incentiva a que otros grupos vulnerables, pero que no son desplazados, se declaren como tal para acceder a los recursos ${ }^{17}$. Esto se convierte en una barrera pues asigna los beneficios estatales a una población que no es la destinataria. Al mismo tiempo, para algunos, el sistema, al estar basado en la entrega de la ayuda humanitaria de emergencia y no en estrategias de generación de ingresos, propicia una pérdida de la capacidad de autonomía y gestión de la PD. "Si bien es cierto la ley tiene muchas bondades, también tiene mucho de asistencialista. Las personas, por ejemplo, se han quedado esperando la ayuda sin hacer nada para empezar a producir. Simplemente estamos en una situación en que la gente está esperando a que el Estado "lo mantenga". Y las ayudas no dan para eso. Entonces se ha creado una cultura asistencialista." 18.

15. El edificio está ubicado a pocas cuadras de la estación "San Pascual" del Sistema de transporte masivo de Cali, en esta hacen paradas los buses articulados cuyas rutas parten de las estaciones de la zona oriente, donde se concentra la PD. Adicionalmente, en los cruces de avenidas y calles, es común encontrar rutas de bus en los sentidos sur y oriente, y algunos jeeps que bajan de la zona de ladera. La Unidad es próxima a la zona de "El Calvario" y al centro de la ciudad donde se ubican casas de inquilinato a las que acuden los desplazados que no cuentan con familiares en la ciudad. No obstante está separada del CAM por más de 10 manzanas.

16. Entrevista a MRR, funcionario del SENA. Junio de 2013

17. Ibáñez A. y Velásquez (2006), explican que en el caso colombiano en que el conflicto es de baja intensidad, el mecanismo para ofrecer la asistencia humanitaria se basa en la demanda por lo que los individuos son quienes deben acercarse a las oficinas del Estado y probar su condición de desplazados para poder obtener los beneficios. No obstante, este tipo de mecanismos pueden crear incentivos para que otros grupos vulnerables de la población se declaren como desplazados del conflicto; también pueden propiciar un sub-registro porque es posible que los individuos afectados no confíen en el Estado o que no tengan la información sobre cómo acceder.

18. Entrevista a Susana, funcionaria de la Personería. Junio de 2013. 


\section{Normativas}

Se refieren al desconocimiento de los funcionarios de las disposiciones legales que regulan el tema del desplazamiento y de los procedimientos que deben seguirse para la declaración y el registro ${ }^{19}$. Dentro de los hallazgos en campo, se encontró que la existencia de esta barrera está ligada a la inestabilidad en los cargos. Muchos de los funcionarios que ingresan por primera vez a la Unidad no conocen de temas de víctimas y la extensa normatividad existente, esto, a pesar de que la mayoría son abogados; sin embargo, su experticia no es precisamente la regulación del conflicto armado y los procedimientos de atención ${ }^{20}$. Adicionalmente, hay una evidente falta de capacitación. Los funcionarios prácticamente se entrenan en la marcha. Pero ello es insuficiente cuando se enfrentan a formatos complejos como el Formulario Único de Declaración, el cual presenta preguntas múltiples para la caracterización de las víctimas: "ahora con la nueva Ley de Víctimas (...) se ha dificultado mucho más el acceso a las personas porque una declaración puede demorar entre hora, horay media, entonces no suplimos las necesidades" ${ }_{21}$. Adicionalmente, muchas de las preguntas que contiene el formulario no son claras para el funcionario. Por ejemplo, en el caso de las guías para indagar sobre alguna condición de discapacidad mental o física, las preguntas son del tipo "dificultad para relacionarse con otros", "dificultad para percibir olores", "se cansa con facilidad", entre otras.

\section{Las barreras individuales}

Estas afectan a las víctimas del desplazamiento al momento de acceder a la ruta de atención y reparación, son:

\section{Disponibilidad de recursos}

Implica la no suficiencia de recursos económicos de la víctima para costear los costos indirectos que generan los trámites de acceso a la ruta de atención. Si bien, los beneficios a víctimas son totalmente gratuitos, la población que pretende beneficiarse debe cubrir costos de transporte hasta las entidades encargadas de orientarles, así como

19. El Comité Internacional de la Cruz Roja y el Programa Mundial de alimentos (2007) corroboró la existencia de esta barrera. Igualmente, la Corte Constitucional señala en Autos como el 092/o8 o el 005/o9 que algunos funcionarios administrativos someten a los desplazados a un eterno peregrinaje institucional y a trámites innecesarios en tanto no suministran información oportuna y completa a la PSDF acerca de sus derechos.

20. Estos procedimientos están determinados en los decretos reglamentarios de la Ley 397 de 1997 y de la Ley 1448 de 2011, así como en diversas circulares de la extinta Acción Social y la actual Unidad Nacional de Víctimas.

21. Entrevista a S., funcionario de la Personería. Junio de 2013 
otros gastos de papelería e incluso alimentación, puesto que la jornada de declaración puede abarcar desde las 8:00 a.m. hasta las 3:0o p.m. o más. De acuerdo con el Auto 219 de 2011, cerca del $47 \%$ de los hogares registrados en el RUPD no tienen un ingreso que supere la línea de indigencia y solamente un $5,8 \%$ de los hogares registrados en el RUPD posee al menos una fuente de ingresos autónoma.

\section{Culturales}

Se refiere al choque producto del contacto con otras formas de ver y experimentar lo social y lo estatal. La población desplazada, por lo general, proviene de zonas con poca o nula presencia del Estado o de dinámicas concentradas en lo local-comunitario. Al llegar a la ciudad, su relación con el estado está mediada por estructuras burocráticas consolidadas que responden a lógicas de papeleo y registro de información que estructuran conocimiento y producen rutinas de interacción (Barrera, 2011). Durante el trabajo de campo, se constataron casos de personas que le confesaban al funcionario el miedo que les producía estar en la ciudad. Por ejemplo, una mujer desplazada del Tolima que declaraba que nunca había salido de su pueblo y que se dedicaba a la agricultura, contaba que no sabía cómo pasar las avenidas y que tampoco sabía cómo iba a alimentar a sus hijos si no podía cultivar, y que no quería acudir a la mendicidad ${ }^{22}$.

\section{Estado de vulnerabilidad}

Se refiere a los daños ocasionados por el conflicto que necesariamente, además de poner en una condición visible de necesidad material y psicosocial a las víctimas, genera una serie de interacciones que imprimen un nuevo significado a la realidad. Los daños generan también una extinción generalizada de lo vivo, poniendo en riesgo su capacidad de supervivencia y en una situación de sensación de inferioridad (Andrade, 2014). Esa sensación de inferioridad la sienten las víctimas al interactuar con los funcionarios, cuando el vigilante del edificio les impide el ingreso, cuando los funcionarios les hacen preguntas o explican algo en términos que no comprenden ${ }^{23}$. En conversaciones informales con las victimas declarantes que se encontraban en la Unidad, salían a relucir frases como "Yo solo quiero que me atiendan como a una persona, ¿no?".

Ese sentimiento de inferioridad que pueden experimentar las víctimas es alimentado por ciertas actitudes de los funcionarios que las infantiliza, lo que limita el intercambio y establece una relación de superioridad: el funcionario protege y ordena, y la víctima es "cobijada". También, se evidencian casos donde el funcionario ve con sospecha a

22. Nota del diario de campo de Septiembre de 2013.

23. Por ejemplo, en la toma del juramento antes de la declaración la cara de las víctimas es de desconcierto en muchos casos porque el funcionario menciona el fundamento normativo y los efectos de una falsa declaración 
la víctima y la interacción se basa en un ejercicio probatorio para establecer si el relato del declarante es verdadero.

Las reacciones personales que puede generar una víctima en el funcionario pueden convertirse en una barrera, sobre todo cuando esas reacciones implican algún comportamiento discriminatorio que además ocasiona que el usuario no sienta la suficiente confianza para hablar, o que a pesar de hacerlo se sienta en una situación de inferioridad y de revictimización que le impide acceder a la información necesaria para el restablecimiento de sus derechos ${ }^{24}$. En este aspecto, la noción de igualdad es importante, de hecho, para los funcionarios entrevistados, no son necesarias las rutas diferenciales: "Yo pienso que todos somos iguales. Que el color no aumenta o descalifica a un ser humano, todos necesitamos ayuda. Todos son víctimas y por [lo] tal, no importa el color, todos tienen derecho." ${ }_{25}$ Esta noción de igualdad en un sentido formal puede generar dificultades en cuanto parte de la invisibilización de las diferencias y es un argumento para negar la discriminación existente hacia ciertos grupos humanos ${ }^{26}$.

\section{Evaluación de las prácticas informales como parte de la evaluación de la ruta de atención a víctimas}

De acuerdo con el Auto 373 de 2016, los problemas detectados por la Corte Constitucional respecto al funcionamiento de la ruta evaluada persisten en temas de registro de tierras, vivienda digna y generación de ingresos. No obstante, también se presentan mejorías en ciertos temas, como la implementación de una base de registro de víctimas unificada y el aumento en el presupuesto para la atención de víctimas, en consecuencia la Corte levanta el estado de cosas inconstitucional respecto a los componentes de participación y de registro. Sin embargo, el trabajo de campo de esta investigación revela que a nivel local son manifiestas la falta de recursos para la ejecución de la ruta y

24. MRR del SENA cuenta que en ocasiones debe atender a personas que le dicen “"yo declaréy después resulté no incluida pero nunca nadie me dijo que yo podía hacer un recurso de reposición, entonces se me pasó el tiempo y como no hice el recurso de reposición que la norma dice, entonces, soy desplazada pero no puedo acceder a los beneficios o a los derechos que la norma dice que tengo". Junio de 2013.

25. Entrevista a GV contratista de la Personería para la toma de declaraciones. Junio de 2013.

26. Las percepciones negativas que poseen los funcionarios de las rutas de atención fueron constatadas por la Corte en los Autos 004 y oos de 2009 sobre grupos indígenas y afros, en los mismos se da cuenta de tratos que no son dignos para una persona víctima del conflicto. $\mathrm{Al}$ respecto de las representaciones que tienen los funcionarios encargados de atender a la población víctima del desplazamiento, la investigación "Miedo y Desplazamiento. Experiencias y Percepciones” de Ana María Jaramillo, Martha Inés Villay Luz Amparo Sánchez demuestra que, para el caso de Medellín son seis las imágenes sobre las que gravitan estas representaciones: campesino, parásito, bárbaro, depredador, problema y sujeto resistente a la guerra (2004: 188). 
de capacitación de funcionarios, los problemas de coordinación administrativa, la alta demanda de población que requiere los servicios, al igual que las percepciones de los funcionarios sobre la población desplazada, lo cual puede convertirse en un obstáculo para ofrecer atención oportuna y acceso material a la población en la etapa de registro.

En este sentido, no basta con una evaluación vertical como la que practica la Corte Constitucional a través de su Sala de Seguimiento, sino que es necesaria una evaluación de impacto de las políticas públicas en la que se considere el rol de los actores involucrados (Bozeman, 2007); en este caso, los funcionarios encargados de poner en marcha la ruta de atención. Bozeman sostiene que esa medición debe realizarse indagando por el significado y las cuestiones problemáticas que en la práctica encierra el concepto de interés público. Si bien el Gobierno es el encargado de promover dicho interés y los valores ligados a él, se trata de un deseo no solo de los ciudadanos, sino también de los mismos administradores públicos: "un ideal (...) se refiere a aquellos resultados que mejor atienden la supervivencia y el bienestar a largo plazo de un colectivo social, interpretado como un 'público".

Por su parte, David Rosenbloom (2007) afirma que el análisis de la administración pública no debe reducirse a una dupla costo-beneficio sino que debe considerar cómo las medidas que se adoptan impactan valores democráticos y constitucionales. Este enfoque en valores, de acuerdo con el autor, es una forma de mantener el sistema de pesos y contrapesos en la evaluación de las medidas (statements) que adopta el ejecutivo para complementar las leyes, especificar o reforzar cierto tipo de valores, deben pasar antes por un filtro (scorecards) que permita identificar cómo la organización se desenvuelve en diferentes dimensiones y encontrar fallas y soluciones. Esto complementado con una serie de proyecciones (Impact statements) útiles para determinar el impacto de las medidas sobre los valores constitucionales, y como mecanismos para la divulgación entre la opinión pública sobre los alcances de una política pública.

En la investigación se utilizaron estas dos aproximaciones para indagar acerca de los valores públicos que se reflejaban en las actuaciones de los funcionarios de la Unidad de Víctimas y que ellos consideraban suficientes para satisfacer las exigencias de la ruta descrita. En el trabajo de campo encontramos que la medición cualitativa de esta apropiación dependía de sus creencias y visiones del mundo, lo que hacía muy complicado identificar una única definición de valor público. Por lo anterior, acudimos a una evaluación de sus estrategias de atención, encontrando que muchas de ellas se basaban en reglas informales propias del contexto de la Unidad y que respondían a lo que se creía que era lo justo o promovía la solidaridad.

Efectivamente, se trata de decisiones que estos funcionarios toman en uso de su discrecionalidad, particularmente motivada por la PD. Dicha discrecionalidad se manifiesta respecto al proceso (el "cómo") que se debe usar para que el objetivo se cumpla, o en referencia al resultado que se desea lograr (el "qué"). El enfoque en proceso o 
resultado puede darse simultáneamente, todo depende de la situación. Finalmente, la discrecionalidad implica una evaluación de la procedencia o improcedencia de las decisiones. Se parte de la base que la discrecionalidad debe ejercerse dentro de un marco legal y que las decisiones de los funcionarios deben ser acordes a este, si lo transgreden habría una ilegalidad o una extralimitación en el cargo que genera responsabilidades (Vinzant y Crothers, 1998).

Con esto en mente, las estrategias de atención informales identificadas se relacionaban con los valores de la solidaridad y la justicia. Sin embargo, en el caso de la atención a las víctimas del conflicto prima la dignidad, la justicia transicional, la igualdad, la buena fe y el debido proceso, entre otros (Cap. II Ley 1448/11). En el caso de estudio, la igualdad, quedaba reducida al postulado "todos somos iguales ante la ley", pero en la práctica sí fue posible identificar un vestigio de trato diferencial afirmativo vinculado al ideal de justicia entendido como "dar a cada quien lo que se merece". Un hallazgo interesante es que de acuerdo con los entrevistados, las estrategias para una buena atención estaban ligadas a la compasión o empatía que el otro podía producir. El Cuadro 1 da cuenta de estos hallazgos.

Por otra parte, es innegable la existencia de funcionarios para los cuales su función pública está ceñida y delimitada únicamente por la ley; estos serían los indiferentes (Herzfeld, 1992). Se trata de aquellos funcionarios en los que no es posible detectar un patrón de atención marcado por valores, sino que su estrategia de atención se reduce al diligenciamiento del formato a partir de las preguntas que este contiene y de las respuestas de la PD. Este tipo de funcionario no se interesa por los detalles particulares, solamente narra la historia desde la perspectiva universalista del formato y sus preguntas, la PD es un cliente más y ellos una pieza para el funcionamiento del entramado burocrático. Este tipo de funcionarios, por lo general, han tenido experiencia en entidades del sector público y están acostumbrados al papeleo, al registro de cifras, al cumplimiento de metas cuantitativas ${ }^{27}$ y a la realización de informes. Su discrecionalidad se enfoca en aspectos formales del proceso, y no están preocupados por el resultado a favor del usuario, sino por el registro de la información que el Estado, en su potestad, puede recaudar de los individuos para clasificarlos y así gobernarlos. La actitud de este tipo de funcionarios genera un obstáculo porque nunca impide trazar un vínculo con la víctima que le permita a esta sentirse en confianza para declarar. Finalmente, se puede decir que desde el punto de vista de los valores constitucionales que sustentan la política pública, para los funcionarios empáticos la solidaridad es el valor que articula y permite el funcionamiento del sistema de atención a víctimas como estructura burocrática, para los indiferentes, es el principio de eficiencia administrativa.

27. En la observación en campo, este tipo de funcionarios eran más "eficientes" en la toma de declaraciones, porque mientras sus colegas indagan por los detalles de un declarante, en ese mismo tiempo ellos tomaban dos y hasta tres declaraciones. 
CUADRO 1

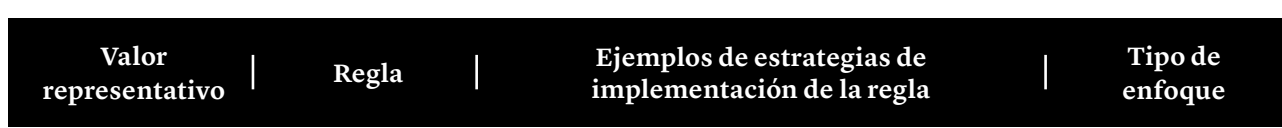

\begin{tabular}{|c|c|c|c|}
\hline Solidaridad & $\begin{array}{l}\text { "El trabajo } \\
\text { funciona } \\
\text { con redes de } \\
\text { contacto" }\end{array}$ & $\begin{array}{l}\text { Asignación de citas adicionales/especiales para } \\
\text { atender a PDD recién llegada a la ciudad si las mis- } \\
\text { mas son remitidas por líderes de organizaciones } \\
\text { de base o por funcionarios amigos del Comité de } \\
\text { la Cruz Roja (CICR). }\end{array}$ & Proceso \\
\hline
\end{tabular}

Remisión directa de casos en urgencia manifiesta

Proceso al CICR para que esta entidad asigne una ayuda humanitaria de emergencia que administra de sus fondos propios.

Llamadas a contactos personales en otras depenProceso y dencias de la Alcaldía que manejan información resultado sobre subsidios de vivienda para población adulto mayor o personas con discapacidad, y de programas de protección de víctimas y defensores de DDHH. Remisión directa de las personas en las condiciones descritas.

"No tirarle
duro a las otras
entidades"

Dado que el trabajo funciona a partir de redes, los N/A entidades" primeros beneficiarios de la solidaridad son los mismos funcionarios. Se procura un trato cordial entre las dependencias, el mismo se traslapa a los informes que semestralmente las entidades presentan donde son cuidadosos a la hora de valorar negativamente el trabajo de sus colegas.

Justicia
"Atender de
acuerdo a la
necesidad y la
urgencia de cada
caso"

Prelación de turnos para personas que asisten

Proceso con algún tipo de enfermedad o discapacidad. Este sistema de preferencia también opera en casos donde la PDD solo acude a la ciudad de Cali a declarar porque su sitio de llegada luego del desplazamiento es un municipio o corregimiento cercano.

La actividad principal en la Unidad es atender a la población usuaria de los servicios que se ofrecen, por lo que tareas como el archivo o el papeleo burocrático pasa a un segundo plano o se evitan al máximo.

Proceso en detrimento de resultados institucionales

En el caso de los funcionarios de declaraciones, utilizar la posición de redactor de la declaración para integrar al relato referencias que puedan ser útiles para que a la hora de la valoración la persona sea incluida en el registro de víctimas. Esto implica tomarse un tiempo extra para poder motivar en la PDD un relato detallado. Esto no se ve como una usurpación de la voz del declarante sino como una ayuda para que sea restituido en sus derechos.
Resultado 


\begin{tabular}{|c|c|c|c|}
\hline \multirow[t]{3}{*}{ Compasión } & $\begin{array}{l}\text { Ayudar con } \\
\text { recursos propios }\end{array}$ & $\begin{array}{l}\text { Pago de transportes a PDD. } \\
\text { Recolección de alimentos entre los funciona- } \\
\text { rios para un declarante o un líder de PSDF en } \\
\text { particular. } \\
\text { - Ante la falta de suministros, en el área de decla- } \\
\text { raciones los funcionarios llevan sus implemen- } \\
\text { tos de oficina (lapiceros y clips) para atender a } \\
\text { la población. }\end{array}$ & N/A \\
\hline & Brindar consejo & $\begin{array}{l}\text { Vinculado a la creencia religiosa, se brinda } \\
\text { consejo a la persona que presenta una profunda } \\
\text { tristeza por la pérdida de un familiar o por el des- } \\
\text { plazamiento. Esto ocurre con mayor frecuencia } \\
\text { entre las funcionarias. }\end{array}$ & $\mathrm{N} / \mathrm{A}$ \\
\hline & $\begin{array}{l}\text { "El funcionario } \\
\text { de la unidad debe } \\
\text { ser como un ángel } \\
\text { de la guarda" }\end{array}$ & $\begin{array}{l}\text { Ligado a la idea de dar consejo, la mayoría de } \\
\text { funcionarios considera que su estancia tiene un } \\
\text { propósito, de esta manera asignan un sentido de } \\
\text { trascendencia a su función y su rol respecto a la } \\
\text { población vulnerable que atienden: deben ser } \\
\text { fuertes pero a la vez sensibles. Aun cuando esto } \\
\text { implique en ocasiones y de forma inconsciente, } \\
\text { infantilizar a la víctima. }\end{array}$ & $\mathrm{N} / \mathrm{A}$ \\
\hline
\end{tabular}

\section{Conclusión}

Al cruzar los hallazgos obtenidos en esta investigación, es decir, las barreras de acceso al SNARIV con las prácticas de atención de los funcionarios, es posible concluir que el uso de esas estrategias son una forma "artesanal" o empírica no sistemática para hacer frente a las barreras institucionales manifiestas en la sobredemanda y la falta de recursos para brindar una atención integral. También, las actitudes de los funcionarios que buscan generar empatía con las víctimas, son formas de suplir a través de la socialización elemental la poca o nula capacitación de funcionarios para una tarea como esta. Sin embargo, estas estrategias son limitadas pues las barreras se insertan en una problemática estructural del Estado, y además en unas estructuras culturales cuya mirada por las víctimas está atravesada por la idea de vulnerabilidad.

Estas barreras se hacen tangibles en el escenario local y a través de sus actores, de ahí que una apuesta para mejorar la atención de la población víctima del conflicto armado debería involucrar a los funcionarios públicos, por ejemplo, con diagnósticos sobre su estatus contractual frente a la administración pública, o sobre sus necesidades psicosociales. Igualmente, comprender aquellas fortalezas y los vacíos que se detectan en las dinámicas cotidianas de estas oficinas del Estado, podría ser útil para introducir medidas que impulsen la efectividad del sistema promoviendo estrategias acordes a las realidades regionales. El rol del Estado en la construcción de paz, se comprende mejor en la interacción entre la ciudadanía y los funcionarios, pues en estos espacios 
de institucionalidad permeada de realidad y cotidianeidad, es donde se manifiestan los imaginarios y las reglas que pueden o no contribuir a la formación de sociedades reparadas en sus lazos y en la reivindicación de derechos como prerrequisito para la democracia.

\section{Referencias}

ANDRADE SALAZAR, J. A. (2014). Complejidad, conflicto armado y vulnerabilidad de niños y niñas desplazados en colombia. El Ágora U.S.B., 14(2), 649-668.

BARBARY, O., y Urrea, F. (. (2004). Gente negra en Colombia. Dinámicas sociopolíticas en Cali y en el Pacífico. Cldse, Ird, Colciencias.

BARRERA, L. (2011). Más allá de los fines del derecho: expedientes, burocracia y conocimiento legal. Íconos. Revista de Ciencias Sociales. (41), 57-72.

BOZEMAN, B. (2007). Public Values and Public Interest: Counterbalancing Economic Individualism.

BUCHELY, L. (2014) Las Burocracias. Estudio preliminar. Bogotá: Siglo del Hombre Editores.

CASTILLO, SALAZAR Y PINZÓN (2008). ¿A dónde ir? Un análisis sobre el desplazamiento forzado. Cali: Programa Editorial Universidad del Valle.

CASTILLO, L. C. (2012). Cali, ciudad pluriétnica, multicultural y de resistencia de negros e indios. En E. Morera A., Historia de Cali Siglo XX. Tomo II (págs.376-411). Santiago de Cali: Universidad del Valle.

CODHES. (2013). La crisis humanitaria en Colombia persiste. El Pacifico en disputa . Bogotá: Documentos Codhes 26.

. (2014a). Desplazamiento masivo y múltiple. Enero-Noviembre de 2013. Bogotá: Informe No. 81 .

. (2014b). Cifras/ Estadísticas históricas del desplazamiento año 1992-2012. Obtenido de http:// codhes.org/index.php?option=com_si\&type=1 Recuperado en junio de 2013.

COMITÉ INTERNACIONAL DE LA CRUZ ROJA (2007). Una mirada a la población desplazada en ocho ciudades de Colombia: respuesta institucional local, condiciones de vida y recomendaciones para su atención. Bogotá: CICR - PMA

DEPARTAMENTO ADMINISTRATIVO PARA LA PROSPERIDAD SOCIAL. (2012). Anexo. Plan Nacional para la Atención y Reparación Integral a las Víctimas. Obtenido de https://www.dnp.gov. co/LinkClick.aspx?fileticket=tbxvV6MoDGg\%3D\&tabid=1080

FIGLEY C. R., (1995). Compassion Fatigue: Coping with Secondary Traumatic Stress Disorder in Those who Treat the Traumatized. New York: Routledge. 
HERZFELD, M. (1992). The Social Production of Indifference. Exploring the Symbolic Roots of Western Bureaucracy. Londres: The University of Chicago Press

IBÁNEZ A. M. y Velasquéz A. (2006). El proceso de identificación de víctimas de los conflictos civiles: una evaluación para la población desplazada en Colombia. DOCUMENTO CEDE 2006-36. Universidad de los Andes. Disponible en: https://core.ac.uk/download/pdf/6617775.pdf

JARAMILLO A. M., Villa M. y Sánchez L. A. (2004), Miedo y desplazamiento: experienciasy percepciones. Medellín: Corporación Región

MOSQUERA C., Laó-Montes A. y Rodríguez C. (2010). Debates sobre la ciudadanía y políticas raciales en las Américas Negras. Bogotá:Universidad Nacional de Colombia, Universidad del Valle y CES.

PERSONERÍA MUNICIPAL DE CALI. (2014). Informe sobre la situación de la población víctima del conflicto armado en Santiago de Cali 2013-2014. Alcadía de Santiago de Cali .

RECALDE C., G. (2013). Impacto del activismo judicial sobre la garantía del derecho a la educación en Santiago de Cali. Precedente Revista Jurídica Vol. 2, 163-204.

RED NACIONAL DE INFORMACIÓN DE LA UNIDAD DE VÍCTIMAS. (2014). Reportes RNI. Obtenido de http://cifras.unidadvictimas.gov.co/Home/Vigencia

RODRÍGUEZ G., C., y Rodríguez F., D. (2010). Cortes y cambios sociales. Cómo la Corte transformó el desplazamiento forzado en Colombia. Bogotá: Antropos.

ROSEnBlOOM, D. H. (2007). Reinventing Administrative Prescriptions: The Case for Democratic-Constitutional Impact Statements and Scorecards. Public Administration Review. American Society for Public Administration, 28-39.

SALAZAR, B., Castillo, M., y Pinzón, F. (2004). Guerra y Distrubución territotorial en el Valle del Cauca. Revista Sociedady Economía en el Valle del Cauca, http://conflictoaprendizaje.univalle.edu. co/Articulos/guerraydistrib.pdf. Recuperado el 24 de 02 de 2013

SHORE, C., \& Wright, S. (1997). Anthropology of Policy: Critical Perspectives on governance and power. New York: Routledge.

SIMONS, H. (2009). Getting Started . En H. Simons, Case Study Reaserch in Practice (págs. 11-66). Oaks, Cal.: SAGE Publications.

VILHENA V., O. (2011). Desigualdad estructural y Estado de Derecho. En C. Rodríguez G., El Derecho en América Latina. Un mapa para el pensamiento jurídico del S.XXI (pp. 25-46). Buenos Aires: Siglo XXI editores .

VINZANT, J. C., y Crothers, L. (1998). Discretion and Legitimacy in Frontline Public Service. En J. C. Vinzant, \& L. Crothers, Street-Level Leadership (págs. 32-68). Washigton, D.C. : Georgetown University Press. 